\title{
Disseminated Fusarium Infection in an Acute Lymphoblastic Leukemia (ALL) Patient after Allogeneic Bone Marrow Transplantation
}

\author{
Serife M. SOLMAZ, Omur G. SEVINDIK, Celal ACAR, Inci ALACACIOGLU, Ozden PISKIN, \\ Guner H. OZSAN, Bulent UNDAR, Fatih DEMIRKAN, M. Ali OZCAN
}

Dokuz Eylul University Faculty of Medicine, Department of Hematology, Izmir, TURKEY

\section{TO THE EDITOR:}

Fusarium is an opportunistic fungal pathogen which has been emerging as a significant cause of mortality and morbidity in the immunocompromised host. ${ }^{1,2}$ Presentation of fusariosis can be local, locally invasive or disseminated when two or more noncontiguous sites are involved. Therapeutic options are scarce and mortality reaches up to $80-90 \%$ in patients subject to allogeneic hematopoietic stem cell transplantation. ${ }^{3}$

A 31-year-old man with relapsed acute lymphoblastic leukemia was admitted to our hospital for allogeneic bone marrow transplantation. He had been treated with BFM protocol and applied central nervous system prophylaxy with intrathecal chemotherapy and radiotherapy due to diagnosis of precursor B cell acute lymphoblastic leukemia in another hospital. During maintainance treatment, ALL relapsed at central nervous system. The central nervous system disease was treated with high dose methotrexate and intrathecal chemotherapy and he was directed to our hospital for allogeneic bone marrow transplantation from his full matched donor. He was transplanted successfully. At the 50 th day post transplantation, he was admitted to the hospital with acute renal failure because of cyclosporin toxicity. During his hospitalization, central nervous sytem relapse occured. Intrathecal chemotherapy and IDA-FLAG (idarubicine, fludarabine, arabinoside $\mathrm{C}$ and filgrastim) chemotherapy was given. At 9th day of chemotherapy, he developed neutropenic fever. His physical examination was normal. Empirical anti-bacterial antibiotherapy with tazobactam-piperacilline $(4 \times 4.5 \mathrm{~g} /$ day $)$ was started. Due to persistant neutropenic fever at the fourth day of antibiotherapy, thorax HRCT was performed. None of the several blood cultures were positive and aspergillus galactomannan antigen was below detectable levels. There were no nodules or fungal infection specific findings on the computed tomography. Empirical antifungal therapy with caspofungin (at initial dose of $70 \mathrm{mg}$ intravenous infusion followed by $50 \mathrm{mg}$ intravenous daily) was initiated. At 3th day of antifungal therapy, paranasal sinus computed tomography $(\mathrm{CT})$ was performed. But there was no positive findings. The serial galactomannan assays were also negative. The optic fundus examination was normal. During follow-up, some macular erythematous skin lesions developed at lower extremities. Necrosis developed at the center of the lesions (figure1). Because of sustained fever and necrotic skin lesions, punch skin biopsy was taken from these lesions after thrombocyte replacement. 


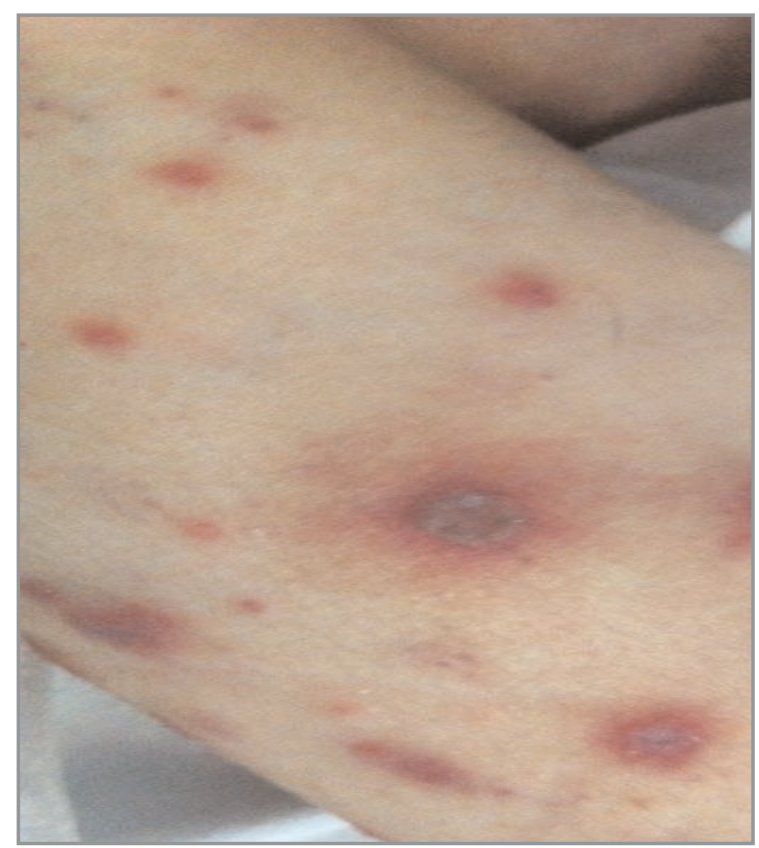

Figure 1. Multiple erythematous lesions with necrosis at the center (like echtyma gangrenosum)

At the pathological examination, non-pigmented, septate non-branching hiphae were detected. At the 8th day of empirical antifungal therapy, caspofungin was replaced with liposomal amphotericin B (5 $\mathrm{mg} / \mathrm{kg}$ /day). However, since the fever persisted, lesions disseminated the whole body, patient's status started deteriorating and new blood cultures were found to be positive for mould infection, voriconazole was added to liposomal amphotericin B. But patient died at the 7th day of combination antifungal therapy.

Fusarium is an opportunistic fungal pathogen which has been emerging as a significant cause of mortality and morbidity in immunocompromised host. ${ }^{1}$ This disease can be local, locally invasive or disseminated when two or more noncontiguous sites are involved. Disseminated infections can cause very high morbidity and mortality. ${ }^{3}$ Unfortunately therapeutic options are scarce. The mainstay of the treatment for disseminated fusariosis has been amphotericin B or its lipid formulations. But mortality reaches $70 \%$ especially in immunocomprimised patients. ${ }^{3.4}$ For immunocomprimised patients, $>70 \%$ was found to have skin involvement. ${ }^{4}$ Our patient was a case with allogeneic bone marrow trasplant and he was neutropenic because of the salvage chemotherapy which was given due to relapsed disease after transplantation. He had developed disseminated skin lesions. In neutropenic patients, all the clues should be evaluated for the diagnosis of the etiology of sustained fever. Possibility of a skin biopsy should be kept in mind to confirm diagnosis. Skin biopsy was made in our patient and septate non-branching hyphaes were seen. So we changed our treatment with a suspect of mould infection.

Voriconazole has been studied in salvage therapy for invasive fungal infections, with efficacy rates for fusarious ranging from $45.5 \%$ to $66 \% .{ }^{5,6}$ Since then, several reports have documented successful treatment of disseminated fusariosis by voriconazole but treatment success is not guaranteed. ${ }^{7}$ In other literatures, combination of antifungal treatments also has been discussed. Successful combination therapies against disseminated fusariosis using amphotericin B products and voriconazole have been reported. ${ }^{89}$ We also used the amphotericin B and voriconazole combination but we lost our patient possibly due to the delay in initiation of secondary antifungal therapy.

As a result, disseminated fusariosis causes high morbidity and mortality in immunocomprimised patients. Optimal treatment modality should be initiated immediately with any suspicion of invasive fungal infection.

\section{REFERENCES}

1. Fleming RV, Walsh TJ, Anaissie EJ. Emerging and less common fungal pathogens. Infect Dis Clin North Am 16: 915-34, 2002

2. Labois A, Gray C, Lepretre S. Successful treatment of disseminated fusariosis with voriconazole in an acute lymphoblastic leukaemia patient. Mycoses 54 Suppl 4:8 -11, 2011.

3. Nucci M, Marr KA, Queiroz-Telles F, et al. Fusarium infection in hematopoietic stem cell transplant recipient. Clin Infect Dis 1237-42, 2004.

4. Boutati El, Anaissie EJ. Fusarium, a significant emerging pathogen in patients with hematologic malignancy: ten years' experience at a cancer center and implications for management. Blood 90: 999 -1008, 1997. 
5. Baden LR, Katz JT, Fishman JA et al. Salvage therapy with voriconazole for invasive fungal infections in patients failing or intolerant to standard antifungal therapy. Transplantation 76: 1632-1637, 2003.

6. Perfect JR, Marr KA, Walsh TJ, et al. Voriconazole treatment for less-common, emerging, or refractory fungal infections. Clin Infect Dis 36: 1122-1231, 2003.

7. Ho DY, Lee JD, Rosso F, et al. Treating disseminated fusariosis: amphotericin B, voriconazole or both? Mycoses 50: 227-231, 2007.

8. Rodriguez CA, Luján-Zilbermann $\mathrm{J}$, Woodard $\mathrm{P}$, et al. Successful treatment of disseminated fusariosis. Bone Marrow Transplant 31: 411-412, 2003.

9. Guzman-Cottrill JA, Zheng X, Chadwick EG. Fusarium solani endocarditis successfully treated with liposomal amphotericin B and voriconazole. Pediatr Infect Dis J 23: 1059-1061, 2004.

\section{Correspondence}

Dr. Mehmet Ali ÖZCAN

Dokuz Eylül Üniversitesi Hastanesi

Hematoloji Anabilim Dalı

Mithatpaşa Cd. 35340, İnciraltı

IZMIR / TURKEY

Tel: (+90.532) 3353721

Fax: (+90.232) 2599723

m-mail: mehmet.ozcan@deu.edu.tr 